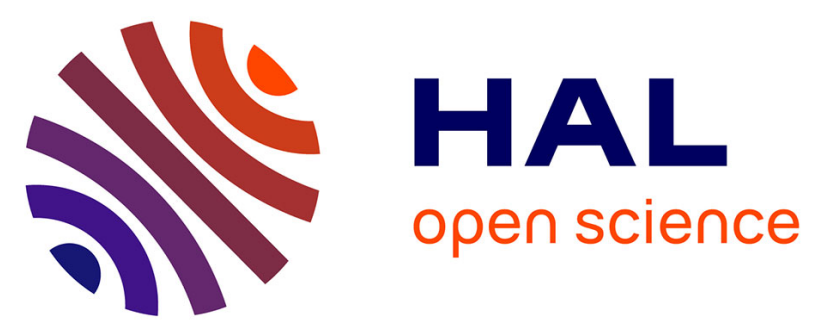

\title{
Titan's atmosphere simulation experiment using continuum UV-VUV synchrotron radiation
}

Zhe Peng, Thomas Gautier, Nathalie Carrasco, P. Pernot, A. Giuliani, Ahmed Mahjoub, Jean-Jacques Correia, A. Buch, Y. Bénilan, Cyril Szopa, et al.

\section{- To cite this version:}

Zhe Peng, Thomas Gautier, Nathalie Carrasco, P. Pernot, A. Giuliani, et al.. Titan's atmosphere simulation experiment using continuum UV-VUV synchrotron radiation. Journal of Geophysical Research. Planets, 2013, 118 (4), pp.778-788. 10.1002/jgre.20064 . hal-00793818

\section{HAL Id: hal-00793818 https://hal.science/hal-00793818}

Submitted on 12 Sep 2020

HAL is a multi-disciplinary open access archive for the deposit and dissemination of scientific research documents, whether they are published or not. The documents may come from teaching and research institutions in France or abroad, or from public or private research centers.
L'archive ouverte pluridisciplinaire HAL, est destinée au dépôt et à la diffusion de documents scientifiques de niveau recherche, publiés ou non, émanant des établissements d'enseignement et de recherche français ou étrangers, des laboratoires publics ou privés. 


\title{
Titan's atmosphere simulation experiment using continuum UV-VUV synchrotron radiation
}

\author{
Z. Peng, ${ }^{1,2}$ T. Gautier, ${ }^{2}$ N. Carrasco, ${ }^{2}$ P. Pernot, ${ }^{1}$ A. Giuliani, ${ }^{3}$ A. Mahjoub, ${ }^{2}$ J.-J. Correia, ${ }^{2}$ \\ A. Buch, ${ }^{4}$ Y. Bénilan, ${ }^{5}$ C. Szopa, ${ }^{2}$ and G. Cernogora ${ }^{2}$ \\ Received 13 December 2012; revised 7 February 2013; accepted 14 February 2013; published 17 April 2013.
}

[1] A new reactor, named APSIS for Atmospheric Photochemistry Simulated by Synchrotron, is designed for simulating the reactivity occurring in planetary upper atmospheres. In this reactor, a gas mixture roughly reproducing Titan's main atmosphere composition $\left(\mathrm{N}_{2} / \mathrm{CH}_{4}=90 / 10\right)$ is irradiated by a continuous spectrum in the $60-350 \mathrm{~nm}$ range, provided by the DISCO beamline at the SOLEIL synchrotron radiation facility. This spectral range enables the dissociation and ionization of $\mathrm{N}_{2}$ and $\mathrm{CH}_{4}$, as observed in plasma reactors and Titan's ionosphere. The neutral products are detected in situ by quadrupole mass spectrometry and collected with a cryogenic trap for ex situ analysis by gas chromatography-mass spectrometry. The detected reaction products include $\mathrm{C} 2, \mathrm{C} 3, \mathrm{C} 4$, and probably $\mathrm{C} 5$ organic compounds, with important amounts of nitrogen-bearing species: $\mathrm{HCN}, \mathrm{CH}_{3} \mathrm{CN}$, and $\mathrm{C}_{2} \mathrm{~N}_{2}$. Neutral mass spectra obtained with APSIS are compared with Ion and Neutral Mass Spectrometer experiments of the Cassini space probe in the upper Titan atmosphere and with other results of current Titan atmosphere chemistry laboratory simulations.

Citation: Peng, Z., et al. (2013), Titan's atmosphere simulation experiment using continuum UV-VUV synchrotron radiation, J. Geophys. Res. Planets, 118, 778-788, doi:10.1002/jgre.20064.

\section{Introduction}

[2] Titan, the largest moon of Saturn, is of great interest for planetary sciences and astrobiology, mainly because its dense atmosphere is the subject of an active and rich organic chemistry, driven by methane $\left(\mathrm{CH}_{4}\right)$ history in the present and past atmosphere [Mandt et al., 2012; Nixon et al., 2012]. More specifically, in the upper atmosphere above $700 \mathrm{~km}$ altitude, the Cassini space mission revealed a complex chemistry initiated by solar EUV-VUV radiation and Saturn magnetospheric electron influx [Carrasco et al., 2007; Cravens et al., 2006; Vuitton et al., 2007; Waite $J r$. et al., 2005]. High-energy radiations partially ionize the gaseous medium mainly composed of molecular nitrogen $\left(\mathrm{N}_{2}\right)$ and methane, leading to a natural plasma with an ionization ratio of about $1 \mathrm{ppm}$ [Larsson et al., 2012]. The ion and neutral chemistry occurring in this atmospheric layer

\footnotetext{
${ }^{1}$ Laboratoire de Chimie Physique, UMR 8000, CNRS, Université Paris-Sud, Orsay, France.

${ }^{2}$ Université Versailles St-Quentin, UPMC Univ. Paris 06, CNRS, LATMOS, Guyancourt, France.

${ }^{3}$ Synchrotron SOLEIL, Gif-sur-Yvette, France.

${ }^{4}$ Laboratoire Génie des Procédés et Matériaux, École Centrale Paris, Châtenay-Malabry, France.

${ }^{5}$ Laboratoire Interuniversitaire des Systèmes Atmosphériques, UMR 7583, Universités Paris VII \& Paris XII, Créteil, France.

Corresponding authors: N. Carrasco, Université Versailles St-Quentin, UPMC Univ. Paris 06, CNRS, LATMOS, 11 Blvd. d'Alembert, 78280 Guyancourt, France. (nathalie.carrasco@latmos.ipsl.fr); A. Giuliani, Synchrotron SOLEIL, L'Orme des Merisiers, Saint-Aubin - BP 48, F-91192, Gif-surYvette, France (alexandre.giuliani@synchrotron.fr).

(C)2013. American Geophysical Union. All Rights Reserved. 2169-9097/13/10.1002/jgre.20064
}

leads to the formation of large organic species consistent with an aerosol initiation in Titan's upper atmosphere [Lavvas et al., 2009; Waite Jr. et al., 2007].

[3] Despite the numerous observations made by the Cassini orbiter [Waite Jr. et al., 2009], the formation mechanism of these heavy species is still poorly understood but may be related with nitrile compounds [Jennings et al., 2012; Vuitton et al., 2006] or polycyclic aromatic hydrocarbons [Sagan et al., 1993]. In order to interpret these observations, two kinds of complementary laboratory studies are realized in gas phase reactors with an energy source initiating the primary ionization and dissociation processes of $\mathrm{N}_{2}-\mathrm{CH}_{4}$ gas mixtures. With plasma discharges, such as in the PAMPRE reactor, energy is deposited through electron impact [Alcouffe et al., 2010; Carrasco et al., 2009; Szopa et al., 2006], whereas VUV monochromatic irradiation has been used in photochemical studies [Imanaka and Smith, 2010].

[4] Plasma discharges are more efficient for the production of aerosols, but Titan's chemistry is mainly driven by photochemical processes. In order to address the issue of the sensitivity of the global chemistry to the energy source, we designed a new photochemical reactor, APSIS - Atmospheric Photochemistry Simulated by Synchrotron - to be coupled with a VUV photon source. The experiment has been mounted on DISCO, a VUV beamline at the SOLEIL synchrotron radiation facility.

[5] Activation of $\mathrm{N}_{2}$ requires VUV wavelengths below $100 \mathrm{~nm}$ (Figure 1). Typical leak tight windows made of $\mathrm{LiF}, \mathrm{CaF}_{2}$, or $\mathrm{MgF}_{2}$ are capable of handling the pressure difference between the ultrahigh vacuum of the beamline and the pressure of the reactor but are opaque below $\sim 110 \mathrm{~nm}$ $(11.3 \mathrm{eV})$, preventing the activation of molecular nitrogen. Photochemical reactors operating at Ly alpha and above therefore focus on methane chemistry [Ádámkovics and 


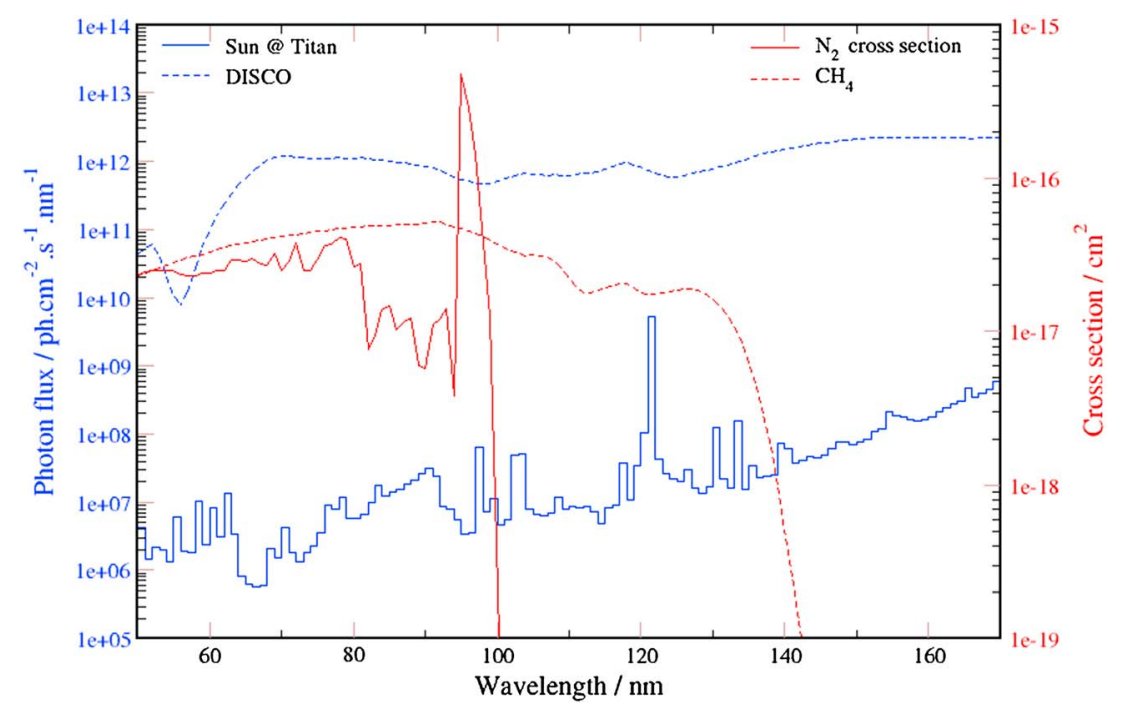

Figure 1. Energy spectra of APSIS and solar spectrum at the top of Titan's atmosphere.

Boering, 2003; Romanzin et al., 2008; Trainer et al., 2004]. Although it is relatively easy to irradiate any media with UV photons through windows, it is much more difficult to deliver to a gas sample VUV photons with energy above the transparency limit of the windows. Therefore, the APSIS chamber is coupled windowless to the DISCO beamline, using a differential pumping system. A nonreactive carrier gas, helium, is continuously injected between the beamline and the APSIS chamber in order to prevent the reactive mixture to be pumped out of the reactor into the differential pumping system. The spectrum of the DISCO beamline is generally $10^{4}-10^{6}$ times more intense than the solar spectrum at Titan but much more uniform and has no peak at $\operatorname{Ly} \alpha, 121.6 \mathrm{~nm}$ (see Figure 1).

[6] This experiment differs significantly from the single previous synchrotron study of Titan's atmosphere [Imanaka and Smith, 2007, 2010], working at 0.066 or 0.13 mbar and using a narrowband synchrotron radiation source. The experiments presented here were done in the same experimental conditions (room temperature and pressure in the millibar range) as in the PAMPRE plasma reactor in order to compare the chemistries generated with photons and electrons.

[7] The experimental setup is detailed in section 2. Specific analytical techniques involving in situ mass spectrometry and ex situ cryogenic trap and its gas chromatograph coupled to a mass spectrometer (GC-MS) analysis are presented in section 3 . The main results addressed in section 4 include the time scale of the experiments in various pressure conditions, GC-MS product identification, and in situ mass spectrometer (MS) product quantification. A comparison with the PAMPRE plasma results, the synchrotron results of [Imanaka and Smith, 2010], and the Cassini INMS measurements is discussed in section 5 .

\section{Experimental Setup}

\subsection{The APSIS Reactor}

[8] The stainless steel reactor is presented in Figure 2. It is a parallelepiped with internal dimensions (width $\times$ length $\times$ height) of $500 \mathrm{~mm} \times 114 \mathrm{~mm} \times 92 \mathrm{~mm}$. The geometry is elongated to accommodate the optical depth of $\mathrm{CH}_{4}$ in the experimental conditions described below. A reactive gas mixture is flowed into the reactor using a $0-10 \mathrm{~cm}^{3} \mathrm{~min}^{-1}$ STP range MKS mass flow controller. A primary pumping unit ensures a stationary flow of reactive gas whose partial pressure reaches a few millibars and a residence time of the gas mixture of a few minutes. The pressure is measured with an absolute capacitance gauge (Ceravac from Oerlikron). Before each experiment, the reactor is pumped down to $\sim 10^{-5}$ mbar by a turbo molecular pump to clean out the chamber from residual gas traces.

\subsection{The DISCO Beamline}

[9] Photon sources covering the VUV nitrogen dissociation energy domain may be found on synchrotron radiation facilities. An important property of synchrotron radiation is its spectrum, covering a wide range of photon energies, from terahertz to hard X-rays. DISCO, a bending magnet based beamline, has been described in more details elsewhere [Giuliani et al., 2009, 2011]. It possesses three end stations. One of those, referred to as APEX (for Atmospheric Pressure Experiment), is fitted with a pressure differential pumping system, which allows delivering monochromatic VUV photons down to $60 \mathrm{~nm}$ up to a rare gas pressure of 1 bar. The reactor was mounted on that particular port.

\subsection{Experimental Parameters}

[10] A gas mixture of $\mathrm{N}_{2} / \mathrm{CH}_{4}=90 / 10$ (purity $>99.999 \%$, Air Liquide) is injected at different flows, resulting in different partial pressures. Partial pressures of $\mathrm{N}_{2}$ and $\mathrm{CH}_{4}$, total pressures with helium, and the corresponding residence times of the gas mixture at the studied gas flows are shown in Table 1. The experiments are conducted at room temperature.

\section{Analytical Techniques}

\subsection{In Situ Mass Spectrometry}

[11] In situ measurement of the gas phase composition is achieved using a Pfeiffer QME 200 quadrupole mass spectrometer (MS), described in detail previously [Carrasco 


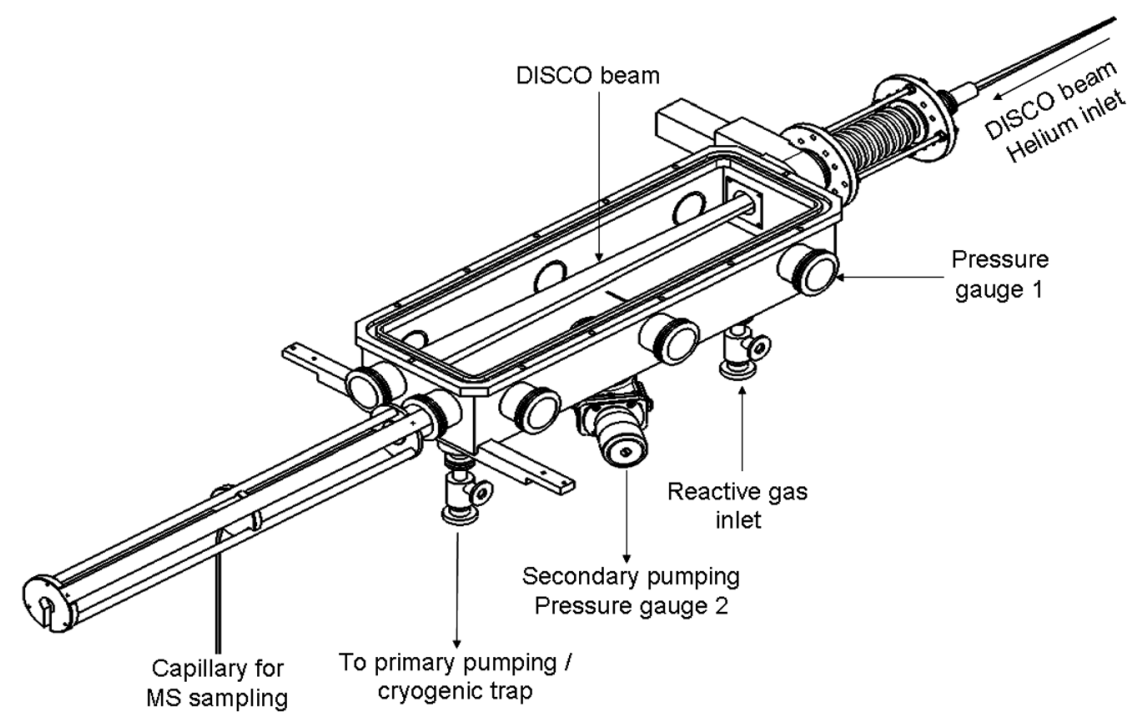

Figure 2. Schematic diagram of the APSIS setup.

Table 1. Experimental Conditions ${ }^{\mathrm{a}}$

\begin{tabular}{|c|c|c|c|}
\hline $\begin{array}{l}\text { Reactive } \mathrm{N}_{2}+\mathrm{CH}_{4} \text { Gas } \\
\text { Flow }\left(\mathrm{cm}^{3} \min ^{-1} \mathrm{STP}\right)\end{array}$ & $\begin{array}{c}\text { Partial Pressure } \\
\text { of } \mathrm{N}_{2}-\mathrm{CH}_{4} \\
(\mathrm{mbar})\end{array}$ & $\begin{array}{l}\text { Total Pressure } \\
\text { With He } \\
\text { (mbar) }\end{array}$ & $\begin{array}{l}\text { Residence Time of } \\
\text { Gas Mixture (min) }\end{array}$ \\
\hline 0.6 & 1.3 & 2.1 & $\sim 11$ \\
\hline 2 & 1.5 & 2.5 & $\sim 4$ \\
\hline 7 & 4.5 & 7.0 & $\sim 3$ \\
\hline 10 & 6.5 & 8.7 & $\sim 3$ \\
\hline
\end{tabular}

${ }^{\text {a}}$ Pressure conditions and residence times of gas mixture in the experiments. Total pressure is measured after the addition of helium.

et al., 2012]. In the MS, neutral molecules are ionized by electron impact at a standard $70 \mathrm{eV}$ electron energy. Gas sampling is done through a capillary tube $(0.8 \mathrm{~mm}$ internal diameter), mobile along the reactor length dimension and radially close to the irradiated column (Figure 2). The capillary tube is long enough to reduce the conductance between the reactor chamber and the MS, which is ideally kept at an operating pressure $P_{\mathrm{MS}}$ below $10^{-5} \mathrm{mbar}$ [Sciamma-O'Brien et al., 2010]. As a consequence, only stable molecules can be measured with this setup. The MS detector has a resolution of 1 unified atomic mass unit (u) and covers the 1 to $100 \mathrm{u}$ mass range.

[12] The DISCO photon flux (a few $10^{11} \mathrm{ph} \mathrm{s}^{-1}$ for $0.1 \mathrm{~nm}$ bandwidth) leads to a nitrogen dissociation ratio of less than $10^{-4}$. The signal at $m / z 28$ of $\mathrm{N}_{2}$ should therefore be constant enough throughout the experiments to be considered as a fixed reference. A slight electronic drift is often observed during the experiments lasting several hours. It affects proportionally all the ion signals, confirmed by a similar drift of the total pressure measurement in the ion source of the mass spectrometer. The intensity of the mass peak at $\mathrm{m} / \mathrm{z} 28$ is therefore used to normalize the mass spectra.

[13] We made two types of experiments in order (i) to monitor the time-dependent evolution of a series of mass peaks during the irradiation (multiple ion detection (MID) measurements) and (ii) to characterize the stationary states before (DISCO OFF) and after (DISCO ON) irradiation on a continuous mass range (scan analogs). Studying the stationary state allows to increase the signal-to-noise ratio by long acquisition time scales: a $10 \mathrm{~s}$ shift is chosen for each mass between $m / z 2$ and 80 .

[14] We monitored the temporal evolution of the gas mixture composition recording the intensity of the maximum of mass peaks of interest in multiple ion detection (MID) mode: $m / z=15,26,27,28,38,39,41$, and 52. The signal at each of these masses was accumulated during $1 \mathrm{~s}$, leading to a total time resolution of $15 \mathrm{~s}$.

[15] As described in Sciamma-O'Brien et al. [2010], the peak at $\mathrm{m} / \mathrm{z} 15$ is representative of methane. A possible contribution of ${ }^{15} \mathrm{~N}^{+}$also occurs for $\mathrm{N}_{2}-\mathrm{CH}_{4}$ gas mixtures, but for a gas mixture with $10 \%$ of methane, this contribution is found to be negligible.

[16] Except for $m / z 28$ dominated by $\mathrm{N}_{2}$ signature, the ion masses chosen in the MID method correspond to product formation in mass regions $\mathrm{C}_{2}, \mathrm{C}_{3}$, and $\mathrm{C}_{4}$, with two, three, or four heavy ( $\mathrm{C}$ or $\mathrm{N})$ atoms bearing species, respectively.

\subsection{Data Treatment of Scan Analogs}

[17] As can be seen on the scan analogs obtained at $10 \mathrm{~cm}^{3} \mathrm{~min}^{-1}$ STP with the DISCO ON and DISCO OFF conditions (Figure 3), productions are not obvious for masses higher than $\mathrm{m} / \mathrm{z} 50$. In order to improve the signal-to-noise ratio for these larger masses, we use two integration methods described below.

\subsubsection{Estimation of the Relative Concentration of the} Major Products Versus $\mathrm{N}_{2}$

[18] In order to determine the intensities of the peaks in the mass spectra, signal integration for each integer $\mathrm{m} / \mathrm{z}$ is applied. Effective signals are obtained by excluding the additive contribution of the baseline [Listgarten and Emili, 2005], assumed constant in a spectrum and estimated by averaging the signals above $m / z 70$ (called the "asymptotic zone" thereafter). Taking into account a peak center shift from integer $m / z$ to the right by $0.2-0.3 \mathrm{u}$, we integrate the baseline-corrected signals in the $\mathrm{m} / z$ interval $[i-0.25$, $i+0.75]$ and affect the result to the intensity at $\mathrm{m} / z i$. Then, all intensities are normalized with respect to $\mathrm{m} / \mathrm{z} 28$, yielding relative intensities. Difference spectra (DISCO ON-DISCO OFF), 


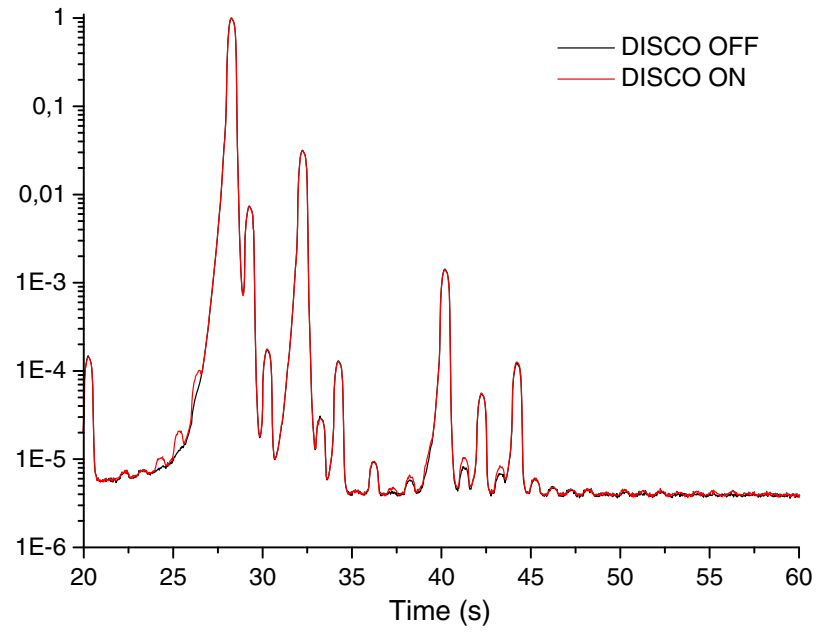

Figure 3. Effect of $\sim 1 \mathrm{~h}$ DISCO irradiation on the $10 \mathrm{~cm}^{3} \mathrm{~min}^{-1} \mathrm{STP}$ reactive gas mixture, with HP in the MS.

calculated from the integrated signals, provide an estimation of the product relative concentrations.

3.2.2. Treatment for Heavy Species $(m / z>45)$

[19] In the present operational conditions, the intensities in the difference spectra (i.e., the productions) of the heavy species are often close to the noise level of the mass spectrometer. To detect any significant production, the occurrence of significant peaks at masses above $\mathrm{m} / \mathrm{z} 45$ has been tested against pure noise. We checked that the signal in the asymptotic zone $(\mathrm{m} / \mathrm{z}>70)$ can be assimilated to white noise (Gaussian distribution, no autocorrelation) in all experiments. The spectra are baseline corrected as described above and normalized to the maximal intensity of the $\mathrm{m} / \mathrm{z} 28$ peak. The cumulated sum of the MS DISCO ON-DISCO OFF difference is calculated, starting the summation from the higher mass $\operatorname{limit}(m / z=80)$. Thereafter, the resulting data are named difference mass spectra cumulated sum (DMS-CS).

[20] Using this procedure, significant deviations of the DMS-CS trace from pure noise are easier to detect than by inspecting the raw or even unit-integrated difference MS. Significant deviations are identified against the 3 sigma (99\%) confidence interval (CI) DMS-CS for pure white noise signals with mean 0 and variances equal to the asymptotic variance of each of the DISCO OFF and DISCO ON signals. The $99 \% \mathrm{CI}$ is defined by $\mathrm{CI}_{99}(k)=[-3 * U(k), 3 * U(k)]$, where $U(k)=\left\{\left(k-k_{\max }+1\right) *\left(u_{\text {On }}^{2}+u_{\text {Off }}^{2}\right)\right\}^{1 / 2}$ where $k$ is the index of the current MS point and $u_{\mathrm{ON}}$ and $u_{\mathrm{OFF}}$ are the standard deviations of the signals in the asymptotic zone.

\subsection{Cryogenic Trap and GC-MS Analysis}

[21] In order to detect and identify low-concentration products, we installed a cryogenic trap on the outlet of the APSIS reactor, upstream of the vacuum pump. The trap, immerged in liquid nitrogen, is a cylindrical glass coil of $1.3 \mathrm{~cm}$ diameter with a total volume of $133 \mathrm{~cm}^{3}$, described in Gautier et al. [2011]. The gas mixture is pumped from the reactor through the cryogenic trap by the primary pump (Figure 2). Products resulting from the reaction inside the reactor condense in the trap according to their phase diagrams. It has been checked that neither nitrogen nor methane condenses in the trap.
[22] The trap is settled on the experiment for $8 \mathrm{~h}$, after which it is isolated and heated up to room temperature. Once evaporated, the trapped products are injected in a gas chromatograph coupled to a mass spectrometer (GC-MS) through a six-port valve to perform direct gas injection. The GC-MS device used is a ThermoScientific GC-Trace with a ThermoScientific DSQ (Dual Stage Quadrupole) II mass spectrometer in quadrupole detection mode. The column is a MXT-QPlot (Restek) of $30 \mathrm{~m}$ length, $0.25 \mathrm{~mm}$ internal diameter, and $10 \mu \mathrm{m}$ stationary phase thickness. The stationary phase in this column is a porous polymer optimized to separate light organic molecules, bearing typically one to five carbon atoms. A temperature programming was used for the analysis, starting with an isotherm at $30^{\circ} \mathrm{C}$ for $5 \mathrm{~min}$, followed by a gradient of $5^{\circ} \mathrm{C} \min ^{-1}$ from $30^{\circ} \mathrm{C}$ to $190^{\circ} \mathrm{C}$, and ending with a second isotherm at $190^{\circ} \mathrm{C}$ for $5 \mathrm{~min}$. The carrier gas is helium $(99.999 \%)$ with a constant flow

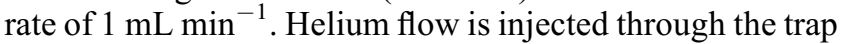
in order to ensure a better introduction of products into the GC. The injector is heated up to $250^{\circ} \mathrm{C}$ and operates in the splitless mode. The temperature of the ion source is set at $200^{\circ} \mathrm{C}$. A blank run is performed before each injection, to ensure that there is no contamination from the previous run.

\section{Results}

\subsection{MS Time-Dependent Measurements}

\subsubsection{Methane Consumption}

[23] The time evolution of the $I_{15} / I_{28}$ ratio of MID signals for an experiment performed at $0.6 \mathrm{~cm}^{3} \mathrm{~min}^{-1} \mathrm{STP}$ is given in Figure 4, where $I_{15}$ and $I_{28}$ are, respectively, the simultaneously measured intensities of the mass peaks at $m / z 15$ and 28. It represents the evolution of the methane to nitrogen ratio during the experiment. The starting time of the photolysis by the DISCO beamline can be easily located by the instantaneous increase of acetylene production detected at $\mathrm{m} / \mathrm{z} 26$ (Figure 4).

[24] Methane relative consumption may be calculated by

$$
\frac{\Delta \mathrm{CH}_{4}}{\left[\mathrm{CH}_{4}\right]_{0}}=\frac{\left(I_{15} / \mathrm{I}_{28}\right)_{0}-\left(I_{15} / \mathrm{I}_{28}\right)_{\mathrm{SS}}}{\left(I_{15} / I_{28}\right)_{0}}
$$

[25] The subscript 0 refers to the initial conditions (before the irradiation by the synchrotron beam) and the subscript SS refers to the steady state conditions when the MS signal reaches an asymptotic value.

[26] The methane relative consumption obtained for different gas flow conditions is reported in Table 2 . The methane relative consumption at SS slightly increases when the gas flow decreases, from a few $10^{-3}$ for $10 \mathrm{~cm}^{3} \mathrm{~min}^{-1}$ STP up to $1 \%$ for $0.6 \mathrm{~cm}^{3} \mathrm{~min}^{-1} \mathrm{STP}$. This evolution is consistent with a dilution effect of the photons: at $0.6 \mathrm{~cm}^{3} \mathrm{~min}^{-1} \mathrm{STP}$, the photons absorbed by methane (in the 100-130 nm wavelength range) penetrate in the reactor for about $15 \mathrm{~cm}$ and only about $3 \mathrm{~cm}$ at $10 \mathrm{~cm}^{3} \mathrm{~min}^{-1} \mathrm{STP}$.

\subsubsection{Time Scale of the Experiments}

[27] The time scale $\tau$ of the experiments is deduced from the time dependence of the $m / z 26$ ion abundance. As seen in Figure 5, this species follows a simple exponential law:

$$
I_{26}(t)=I_{26_{\mathrm{ss}}}-\left(I_{26_{\mathrm{ss}}}-I_{26_{0}}\right) \times \exp \left(-\frac{t}{\tau}\right)
$$

where $I_{26_{\mathrm{ss}}}$ is the stationary intensity of $I_{26}, I_{26_{0}}$ the initial intensity (before irradiation), and $\tau$ the time scale of the observed evolution. 


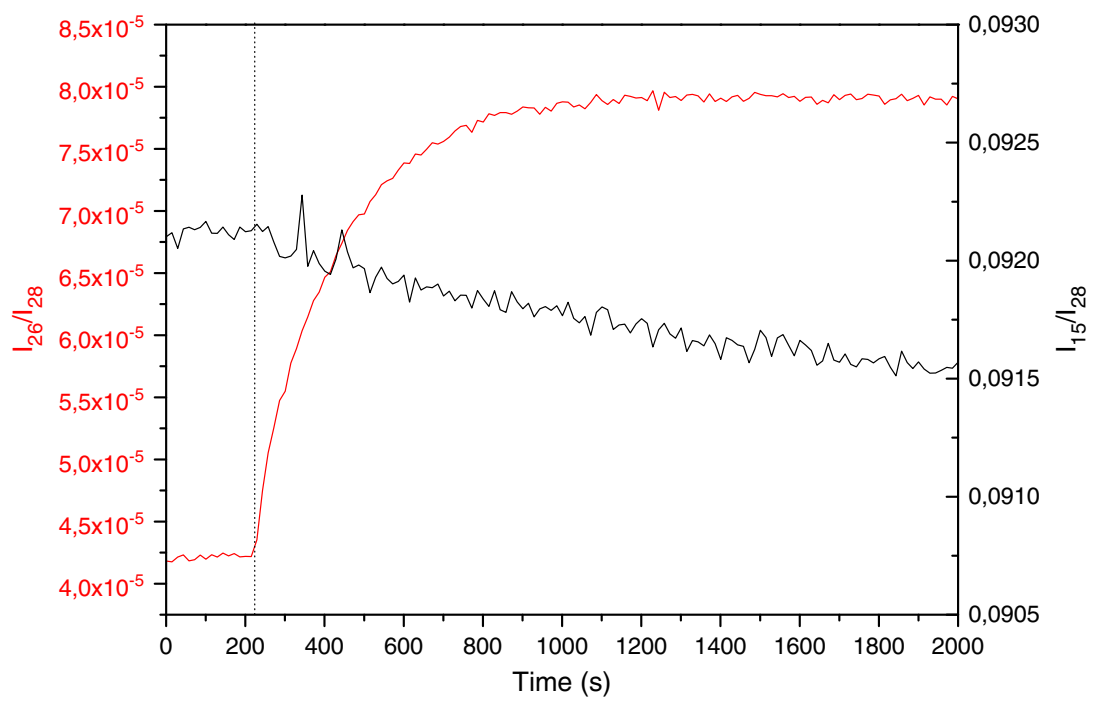

Figure 4. Monitoring of methane consumption $\left(I_{15} / I_{28}\right)$ (black, right axis) and acetylene production $\left(I_{26} / I_{28}\right)$ (red, left axis) for $7 \mathrm{~cm}^{3} \mathrm{~min}^{-1} \mathrm{STP}$ of injected $90-10 \mathrm{~N}_{2}-\mathrm{CH}_{4}$ gas mixture. The irradiation start is depicted by the vertical dashed line at $200 \mathrm{~s}$.

Table 2. Methane Relative Consumption ${ }^{\mathrm{a}}$

\begin{tabular}{lcc}
\hline $\mathrm{N}_{2}+\mathrm{CH}_{4}$ Gas Flow $\left(\mathrm{cm}^{3} \mathrm{~min}^{-1} \mathrm{STP}\right)$ & $\frac{\Delta\left[\mathrm{CH}_{4}\right]}{\left[\mathrm{CH}_{4}\right]_{0}}$ & $\sigma\left(\frac{\Delta\left[\mathrm{CH}_{4}\right]}{\left[\mathrm{CH}_{4}\right]_{0}}\right)$ \\
\hline 0.6 & $1.7 \times 10^{-2}$ & $0.3 \times 10^{-2}$ \\
2 & $4.6 \times 10^{-3}$ & $1.0 \times 10^{-3}$ \\
7 & $3.4 \times 10^{-3}$ & $0.6 \times 10^{-3}$ \\
7 & $3.0 \times 10^{-3}$ & $0.6 \times 10^{-3}$ \\
7 & $3.7 \times 10^{-3}$ & $1.7 \times 10^{-3}$ \\
10 & $3.2 \times 10^{-3}$ & $0.2 \times 10^{-3}$ \\
\hline
\end{tabular}

${ }^{\mathrm{a}}$ Obtained for gas flows increasing from 0.6 to $10 \mathrm{~cm}^{3} \mathrm{~min}^{-1} \mathrm{STP}$.

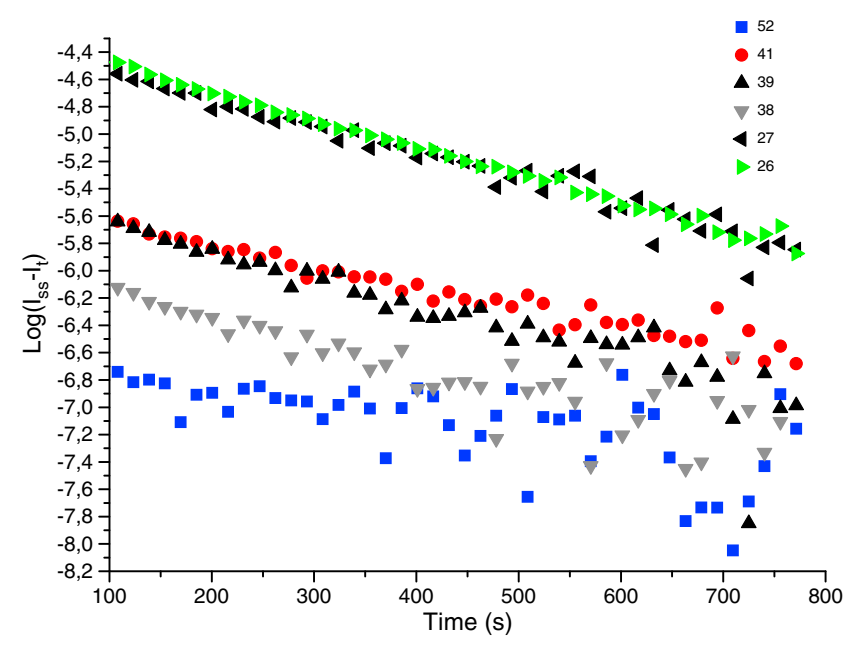

Figure 5. Time-dependent evolution of the parameter log $\left(I_{\mathrm{ss}}-I_{t}\right)$ for an experiment led at $10 \mathrm{~cm}^{3} \mathrm{~min}^{-1} \mathrm{STP}$, for $m / z 26,27,38,39,41$, and 52 .

[28] The time scale $\tau$ is obtained by a linear fit of $\log$ $\left(I_{26 s s}-I_{26 t}\right)=-t / \tau+\log \left(I_{26 s s}-I_{260}\right)$ (Figure 5). The time scale is of about $5-8 \mathrm{~min}$ in all the gas flow conditions studied: from $320 \mathrm{~s}$ at $0.6 \mathrm{~cm}^{3} \mathrm{~min}^{-1} \mathrm{STP}$ and up to $500 \mathrm{~s}$ at $10 \mathrm{~cm}^{3} \mathrm{~min}^{-1}$ STP, comparable to the residence time of the gas in the reactor, of a few minutes.

\subsubsection{Products Formation Kinetics}

[29] Species with mass signatures at $m / z 26,27,38,39,41$, and 52 are produced simultaneously with methane consumption (see Figure 5), showing a production of $\mathrm{C} 2, \mathrm{C} 3$, and $\mathrm{C} 4$ species. Even if the MS peak intensities are not directly representative of the corresponding neutral concentrations due to the different ionization thresholds and fragmentation patterns of the products, the ratio of the main peaks intensities against the one at $\mathrm{m} / \mathrm{z} 28$ provides a rough estimation of the mole fraction of the products diluted in $\mathrm{N}_{2}$. Figure 6 informs us that the products mole fractions are about $10^{-5}$ for $\mathrm{C} 2$ compounds and around the ppm for $\mathrm{C} 3$ and $\mathrm{C} 4$ species.

[30] The calculated time scales for the above-mentioned masses in the $10 \mathrm{~cm}^{3} \mathrm{~min}^{-1} \mathrm{STP}$ experiments are reported in Table 3. A slight increase of the time scale is observed with the size of the products: from about $500 \mathrm{~s}$ for $\mathrm{C} 2$ compounds, up to $600-700 \mathrm{~s}$ for $\mathrm{C} 3$, and up to $1000 \mathrm{~s}$ for $\mathrm{C} 4$ compounds, in agreement with a sequential growth process.

[31] The overlap of the fragments in the MS does not allow to explicitly identify those products. For example, the mass peak at $m / z 27$ could be given by $\mathrm{HCN}^{+}$or the fragment ion $\mathrm{C}_{2} \mathrm{H}_{3}^{+}$of $\mathrm{C}_{2} \mathrm{H}_{4}$. In order to rectify this ambiguity, we accumulated the products in a cryogenic trap and analyzed the content by GC-MS.

\subsection{Products Identification With the Cryogenic Trapping-GC-MS Analysis}

[32] The GC-MS analysis of products accumulated during 8 running hours of a $7 \mathrm{~cm}^{3} \mathrm{~min}^{-1}$ STP experiment is shown in Figure 7. It confirms the detection of $\mathrm{C} 2, \mathrm{C} 3$, and $\mathrm{C} 4$ compounds by in situ mass spectrometry MID analysis. If we assume that the GC-MS response is the same for $\mathrm{C} 2$ to $\mathrm{C} 4$ compounds, we can also assume that the concentration of the C2 compound is larger than $\mathrm{C} 3$ and $\mathrm{C} 4$ compounds. More interestingly, GC-MS enables the unambiguous identification of the major $\mathrm{C} 2$ species, such as ethane $\left(\mathrm{C}_{2} \mathrm{H}_{6}\right)$, ethylene $\left(\mathrm{C}_{2} \mathrm{H}_{4}\right)$, and acetylene $\left(\mathrm{C}_{2} \mathrm{H}_{2}\right)$; the major C3 compounds (acetonitrile $\mathrm{CH}_{3} \mathrm{CN}$, propane $\mathrm{C}_{3} \mathrm{H}_{8}$, and 


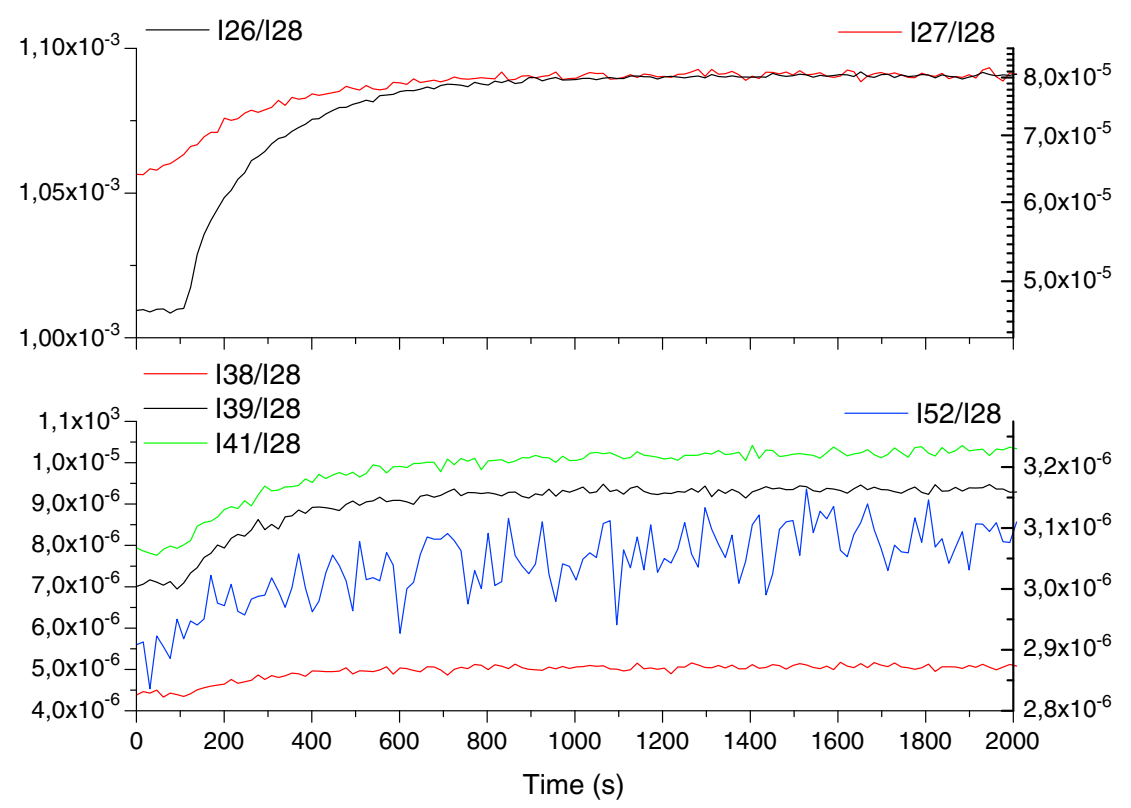

Figure 6. Time monitoring of products for a $10 \mathrm{~cm}^{3} \mathrm{~min}^{-1} \mathrm{STP}$ experiment.

Table 3. Production Time Scales ${ }^{\mathrm{a}}$

\begin{tabular}{|c|c|c|c|c|c|c|}
\hline$m / z$ & 26 & 27 & 38 & 39 & 41 & 52 \\
\hline $\begin{array}{l}10 \mathrm{~cm}^{3} \min ^{-1} \text { STP } \\
0.6 \mathrm{~cm}^{3} \mathrm{~min}^{-1} \text { STP }\end{array}$ & $\begin{array}{l}500 \pm 10 \mathrm{~s} \\
320 \pm 20 \mathrm{~s}\end{array}$ & $515 \pm 30 \mathrm{~s}$ & $645 \pm 120 \mathrm{~s}$ & $490 \pm 60 \mathrm{~s}$ & $705 \pm 50 \mathrm{~s}$ & $990 \pm 360 \mathrm{~s}$ \\
\hline
\end{tabular}

${ }^{\mathrm{a}}$ For the peaks at $m / z 26,27,38,39,51$, and 52 .

propene $\mathrm{C}_{3} \mathrm{H}_{6}$ ); and $\mathrm{C} 4$ compounds (2-butene $\mathrm{C}_{4} \mathrm{H}_{8}$ and ethane dinitrile $\mathrm{C}_{2} \mathrm{~N}_{2}$ (cyanogen)). Hydrogen cyanide, $\mathrm{HCN}$, is not clearly detected in the cold trap, but it could be coeluted with water, leading to the large peak at 17-18 min in the chromatogram.

\subsection{Effect of Enhancing the Pressure in the Mass Spectrometer}

[33] The low mole fractions of about $10^{-5}$ observed by MID for the major products in $\mathrm{C} 2$ and $\mathrm{C} 3$ are near the detection limit of the MS. The use of this instrument in standard conditions prevents therefore any detection of products with lower concentrations, in particular for heavier compounds.

[34] In order to enhance the dynamic range and, consequently, the sensitivity of the MS detection, we performed a second series of experiments in the same conditions as described in Table 1, with a shortened sampling capillary length between the APSIS reactor and the MS. The pressure reached in the ionization chamber of the MS increased from $P_{\mathrm{MS}}=10^{-6}$ mbar (LP (low pressure)) in the first set of experiments up to $P_{\mathrm{MS}}=10^{-4}$ mbar (HP (high pressure)) in the second case. The effects are illustrated in Figure 8, on the example of a $10 \mathrm{~cm}^{3} \mathrm{~min}^{-1} \mathrm{STP}$ experiment. The baseline intensity is actually efficiently decreased from about $2 \times 10^{-5}$ down to $4 \times 10^{-6}$, enabling to detect previously invisible products.

[35] However, this pressure increase in the MS is not without undesirable consequences. A secondary effect is observed at high pressure in the MS in Figure 8: the ratio $I_{14} / I_{28}$ reflecting the cracking pattern of $\mathrm{N}_{2}$ is lower than that at low pressure. The ratio between these two mass peaks should ideally be pressure independent, cracking patterns being defined by the direct and the dissociative ionization pathways of the reaction between molecular nitrogen and electrons at $70 \mathrm{eV}$ in the ionization chamber.

[36] In order to further study this unsuitable effect, we introduced only molecular nitrogen in the MS, at various pressures. Results are given in Figure 9. A constant $I_{14} / I_{28}$ ratio is obtained for $P_{\mathrm{MS}}$ between $2 \times 10^{-7}$ and $6 \times 10^{-6}$ mbar, but a strong nonlinear behavior is observed above $P_{\mathrm{MS}}=6 \times 10^{-6}$ mbar.

[37] The operating instructions of the instrument recommend to work with pressures no larger than $P_{\mathrm{MS}}=10^{-5} \mathrm{mbar}$ in the ion source with the secondary electron multiplier as a detector, in spite of the possibility to use the filament up to a pressure of $P_{\mathrm{MS}}=10^{-4}$ mbar. Mao and Leck [1987] and Tilford [1994] reported that nonlinear sensitivities can actually be observed at pressures in the range $10^{-5}-10^{-4}$ mbar, possibly due to ion space charge effects. Some variations of cracking patterns of $\mathrm{H}_{2}$ and $\mathrm{H}_{2} \mathrm{O}$ have also been reported at high pressure by Breth et al. [1983]. We show that an evolution of the cracking pattern of $\mathrm{N}_{2}$ can also be observed at pressures below $P_{\mathrm{MS}}=10^{-5}$ mbar. We have checked that this effect does not depend on the gas temperature (temperature lowered from room temperature down to about $200 \mathrm{~K}$ ) and that no cross sensitivity is observed by mixing nitrogen with a second gas like argon, helium, or hydrogen. 

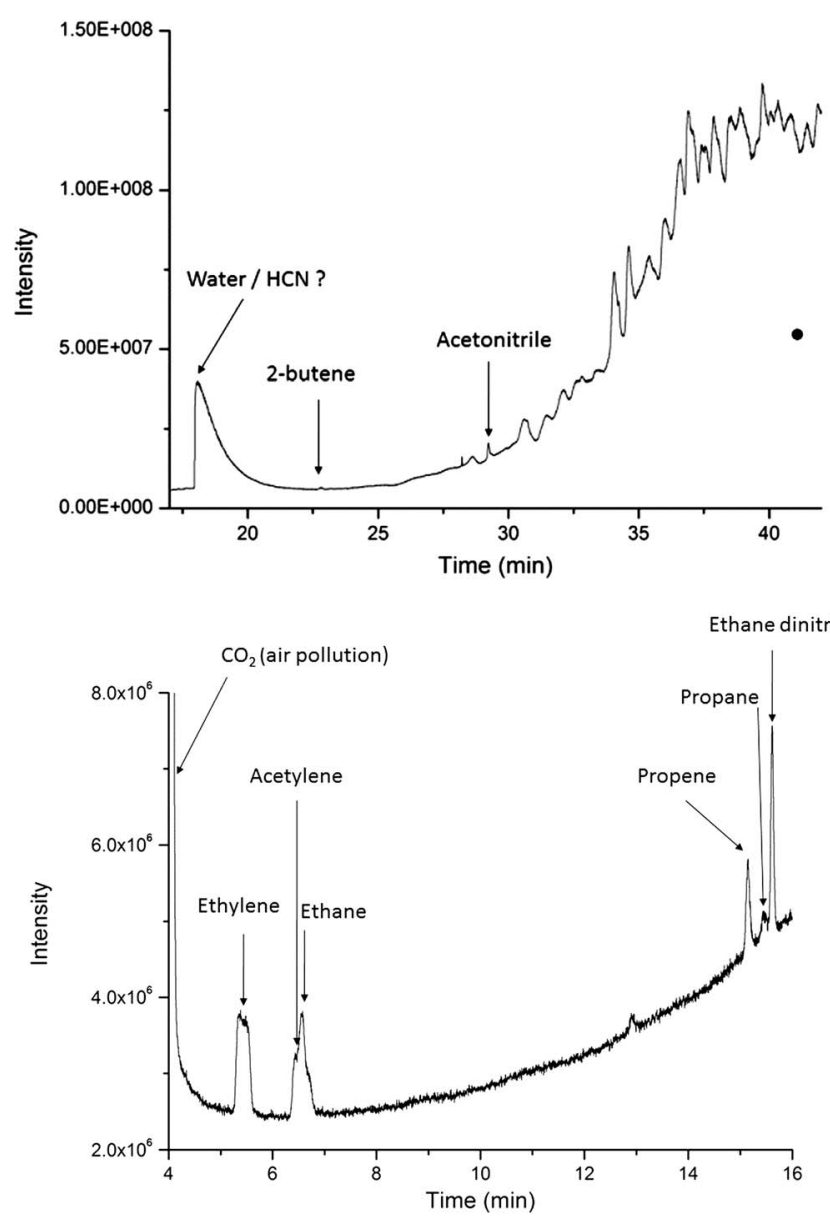

Figure 7. Chromatograms of the sample evaporated from the cryogenic trap.

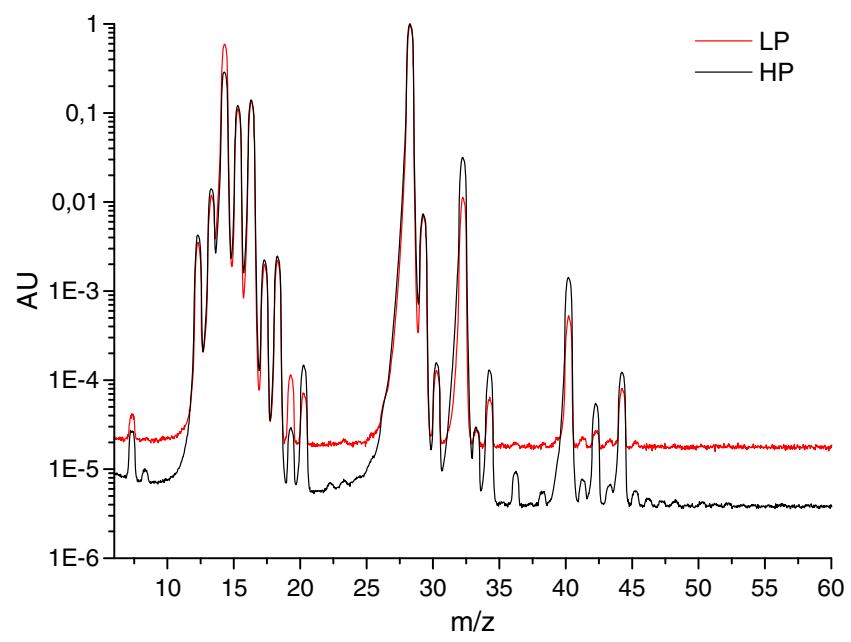

Figure 8. Comparison of the scan analog initial mass spectra obtained for similar $10 \mathrm{~cm}^{3} \mathrm{~min}^{-1}$ STP experimental conditions in the cases of (in red) a low $10^{-6}$ mbar pressure condition in the MS and (in black) a high $10^{-4}$ mbar pressure condition in the MS.

[38] The nonlinear effects, detected at high $P_{\mathrm{Ms}}$ pressures on the $I_{14} / I_{28}$ signature, are certainly affecting the
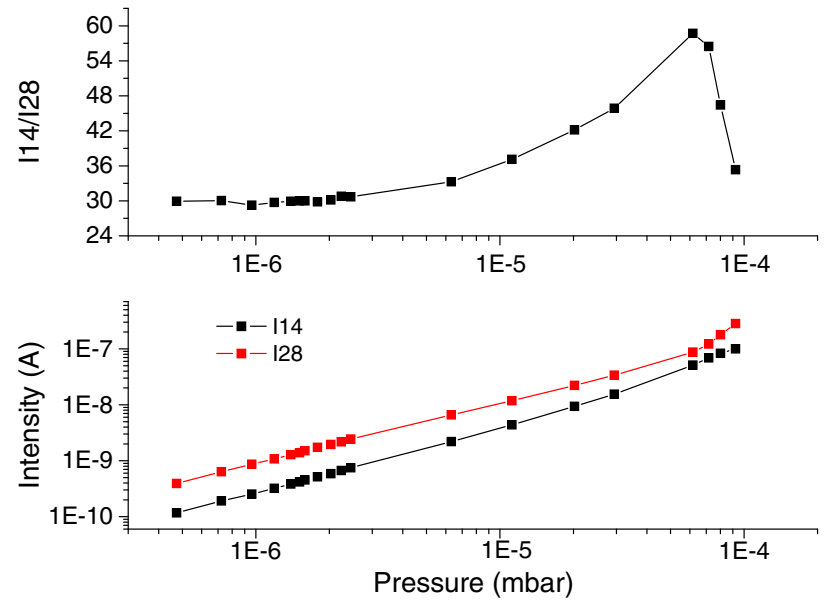

Figure 9. (Lower panel) Evolution of $I_{14}$ and $I_{28}$ for a pure nitrogen influx in the MS, at various pressure conditions; (upper panel) pressure dependence of the ratio $I_{14} / I_{28}$.

cracking patterns of other species and prevent us from any quantitative analysis. Nevertheless, in order to detect products with smaller concentrations in the scan analog MS configuration (see section 3), we favored a high $P_{\mathrm{MS}}$ pressure condition in the mass spectrometer for the rest of the study $\left(P_{\mathrm{MS}}=\mathrm{a}\right.$ few $\left.10^{-5} \mathrm{mbar}\right)$, as done also by Imanaka and Smith [2007, 2010].

\subsection{Products Detection by Mass Spectrometry}

[39] The difference spectra, generated as described in section 3.2, are calculated at all working flow rates: 0.6, 2, 7, and $10 \mathrm{~cm}^{3} \mathrm{~min}^{-1}$ STP (Figure 10). We observe that photochemical products appear at all flow rates in the $\mathrm{C} 2$ $(\mathrm{m} / \mathrm{z} 25-30), \mathrm{C} 3(\mathrm{~m} / \mathrm{z} 38-44)$, and C4 $(\mathrm{m} / \mathrm{z} 49-57)$ regions. However, only the production of $\mathrm{C} 2$ compounds is seen unambiguously for all conditions. The productions of $\mathrm{C} 3$ and $\mathrm{C} 4$ species become significant only at higher flow rates $\left(7 \mathrm{~cm}^{3} \mathrm{~min}^{-1}\right.$ STP and $\left.10 \mathrm{~cm}^{3} \mathrm{~min}^{-1} \mathrm{STP}\right)$, except for $\mathrm{C}_{3} \mathrm{H}_{8}$ at $m / z 44$.

[40] For experiments which have been repeated, some differences are noticeable, but they decrease with increasing gas flow, as expected from the signal-to-noise ratio improvement. However, a few masses with densities above the noise level at $\mathrm{m} / z 27,29,31$, and 33 display repeatability issue. These mass peaks are located in the wings of the peaks of intense species (visible in Figure 3), $\mathrm{N}_{2}$ and $\mathrm{O}_{2}$ $\left(\mathrm{O}_{2}\right.$ from the residual air in the MS, as described in Carrasco et al. [2012]). A slight variation in the peak shape between two scan analogs is sufficient to perturb the integrated mass spectra difference for these species.

[41] As a result of low influx, the pressure in the reactor is low, so is it in the MS: $P_{\mathrm{MS}}$ increases from $2.7 \times 10^{-5} \mathrm{mbar}$ for the experiment at $0.6 \mathrm{~cm}^{3} \mathrm{~min}^{-1}$ STP up to $2.0 \times 10^{-4}$ mbar for the experiments at $10 \mathrm{~cm}^{3} \mathrm{~min}^{-1} \mathrm{STP}$. Working at low pressure elevates the baseline level and leads to a smaller dynamic range of the spectrum (see Figure 8). The product signals seem not high enough to be significantly detected considering the low signal-to-noise ratio in these conditions. As, in the higher mass range $(\mathrm{m} / \mathrm{z} 45-80)$ of our experiments, the abundances are low, the DMS-CS (see section 3.2) is plotted in Figure 11 for all the experiments. One sees that 


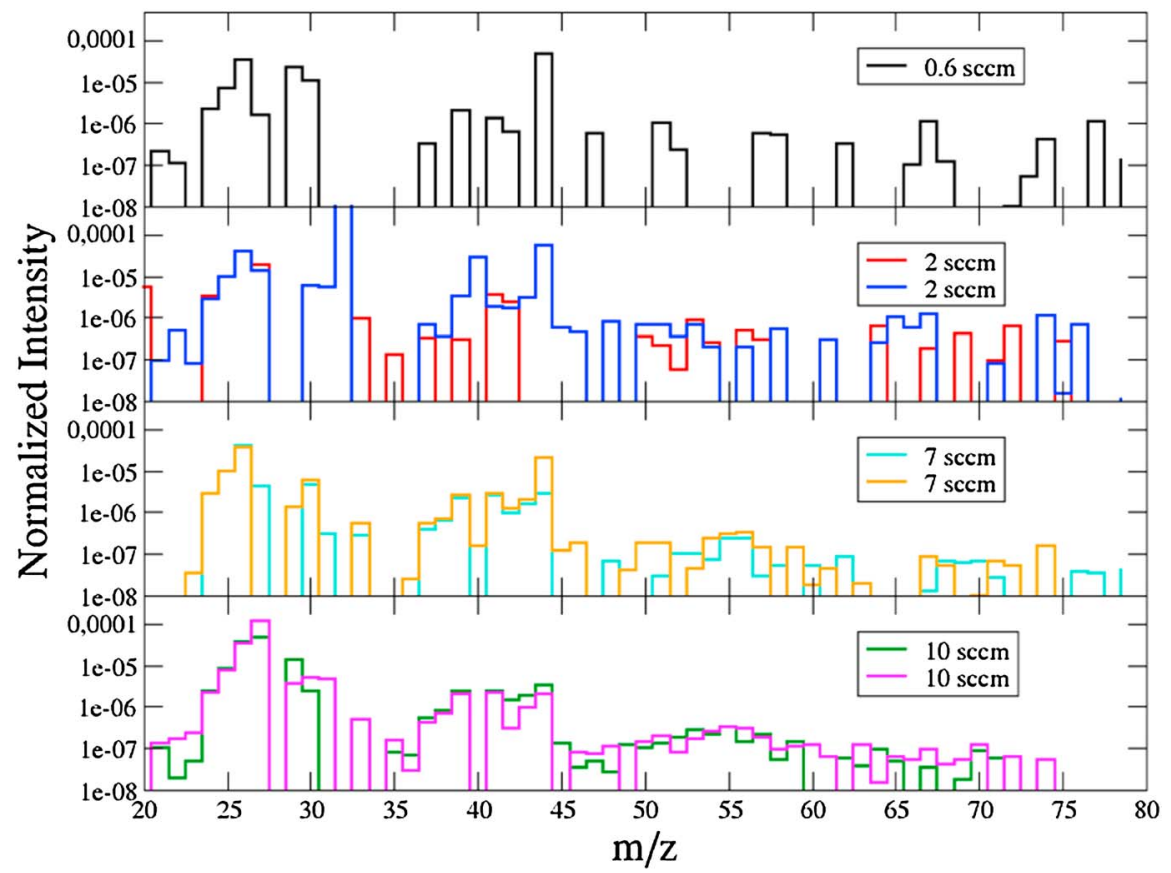

Figure 10. Difference between the MSs of the initial state and the state after $\sim 1 \mathrm{~h}$ irradiation obtained for various gas flows in the APSIS reactor (and HP conditions in the MS).

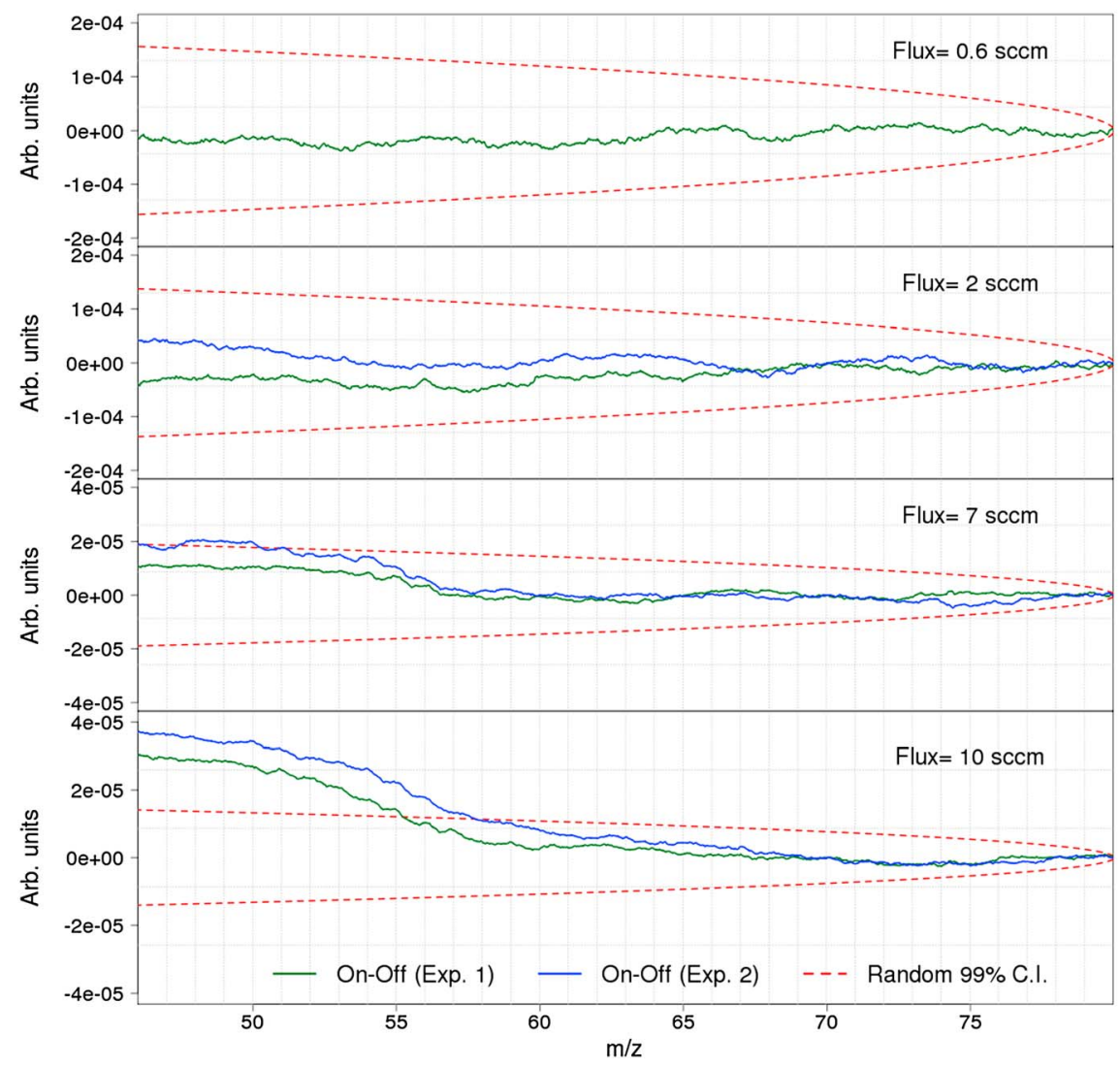

Figure 11. Cumulated sum of "ON-OFF » MS differences (DMS-CS) for the different available pressure conditions (blue and green curves). The DMS-CS is computed starting from the higher masses. It is compared with the $99 \%$ confidence interval for the DMS-CS between two Gaussian random variables with mean 0 and variances equal to the asymptotic variance of the ON and OFF signals (red dash). 
at 0.6 and $2 \mathrm{~cm}^{3} \mathrm{~min}^{-1} \mathrm{STP}$, the experimental signals do not depart from the pure noise limits. It is therefore illusory to detect any product in this mass range. At $7 \mathrm{~cm}^{3} \mathrm{~min}^{-1} \mathrm{STP}$, both experiments rise above pure noise at masses below $m / z 56$, revealing the presence of $\mathrm{C} 4$ compounds, albeit in barely detectable densities. The situation is improved at $10 \mathrm{~cm}^{3} \mathrm{~min}^{-1} \mathrm{STP}$, where the $\mathrm{C} 4$ group is significantly rising above pure noise. The systematic departure from the null axis of both experiments hints to some signal emerging in the $\mathrm{C} 5$ range, below $m / z 70$, but still below the significance limit.

[42] We therefore focus on the higher gas flow conditions, 7 and $10 \mathrm{~cm}^{3} \mathrm{~min}^{-1} \mathrm{STP}$. When the flow rate increases from $7 \mathrm{~cm}^{3} \min ^{-1} \mathrm{STP}$ to $10 \mathrm{~cm}^{3} \mathrm{~min}^{-1} \mathrm{STP}$, the relative intensities are globally preserved. The $\mathrm{C} 2, \mathrm{C} 3$, and $\mathrm{C} 4$ relative concentrations can be calculated from the spectra in Figure 10: C2 is around $10^{-5}, \mathrm{C} 3$ around $10^{-6}$, and C4 slightly higher than $10^{-7}$. This expected trend of decreasing relative concentrations with the heavy atom number is predicted in Dobrijevic and Dutour [2006] and observed by Dobrijevic and Dutour [2006], Gautier et al. [2011], and Thejaswini et al. [2011].

\section{Discussions}

[43] We compared in Figure 12 the neutral mass spectrum obtained at $10 \mathrm{~cm}^{3} \mathrm{~min}^{-1}$ STP with the APSIS experiment with other neutral compositions observed in several cases of interest for Titan atmospheric study: (a) the neutral mass spectrum obtained with the PAMPRE plasma discharge [Carrasco et al., 2012], (b) the neutral mass spectrum obtained with a synchrotron radiation experiment with $60 \mathrm{~nm}$ photons [Imanaka and Smith, 2010], and (c) a measurement of the INMS mass spectrometer on board Cassini [Waite Jr. et al.,

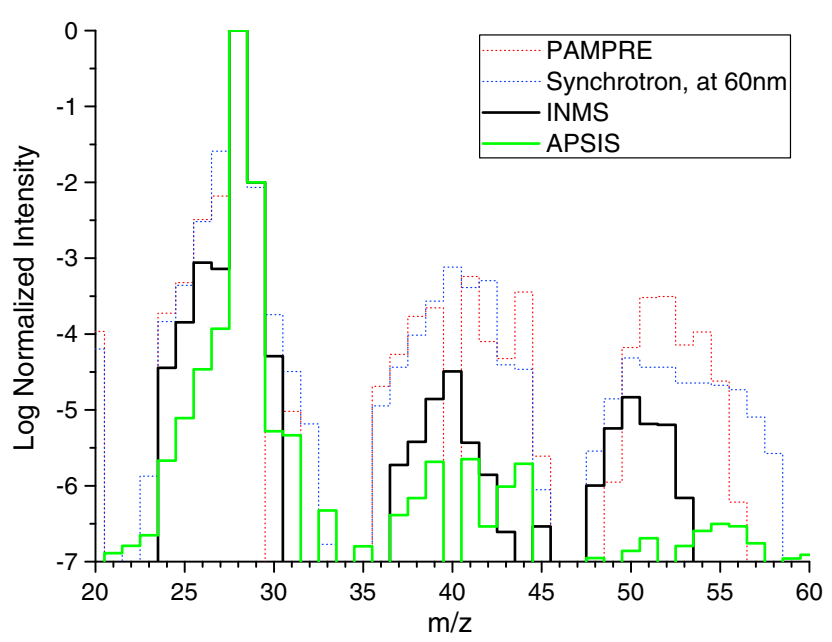

Figure 12. Mass spectra of neutral species in (a) the PAMPRE plasma discharge study [Carrasco et al., 2012] (red dot), (b) a synchrotron experiment at $60 \mathrm{~nm}$ reported in Imanaka and Smith [2010] (blue dot), (c) Titan atmosphere measured by the INMS [Waite Jr. et al., 2007] (black solid), and (d) the APSIS experiment at $10 \mathrm{~cm}^{3} \mathrm{~min}^{-1} \mathrm{STP}$ (green solid). The intensities at $m / z=28$ and 29 , corresponding to $\mathrm{N}_{2}$, in Figures $12 \mathrm{a}$ and $12 \mathrm{~d}$ are artificially added for convenience in comparison.
Table 4. Order of Magnitude of the Neutral Product Mixing Ratios $^{\mathrm{a}}$

\begin{tabular}{lccc}
\hline Mass Spectra & $\mathrm{C} 2$ & $\mathrm{C} 3$ & $\mathrm{C} 4$ \\
\hline PAMPRE, plasma & $10^{-3}$ & $10^{-4}$ & $10^{-5}-10^{-4}$ \\
Synchrotron, 60 nm & $10^{-3}$ & $10^{-4}$ & $10^{-5}$ \\
INMS & $10^{-4}$ & $10^{-6}-10^{-5}$ & $10^{-6}-10^{-5}$ \\
APSIS & $10^{-5}$ & $10^{-6}$ & $10^{-7}$ \\
\hline
\end{tabular}

a Observed in Titan atmosphere (INMS), in a synchrotron experiment at $60 \mathrm{~nm}$ [Imanaka and Smith, 2010], in the plasma PAMPRE experiment [Carrasco et al., 2012], and in APSIS.

2007]. We have chosen the $m / z 20-60$ range to focus on the significant productions observed with the APSIS experiment, corresponding to the $\mathrm{C} 2, \mathrm{C} 3$, and $\mathrm{C} 4$ compounds. In the experimental simulations, the peaks at $\mathrm{m} / \mathrm{z} 40$ and 44 are often disturbed by a contribution of argon and carbon dioxide, respectively, due to residual air signature in the system. The productions at these masses should therefore not be further considered.

[44] A general decrease of the intensities with the size of the detected species is well observed in all spectra, but with differing orders of magnitude, reported in Table 4. The product mixing ratios in the $60 \mathrm{~nm}$ synchrotron irradiation [Imanaka and Smith, 2010] and in the PAMPRE plasma discharge [Carrasco et al., 2012] are one order of magnitude higher than that in Titan INMS spectra and about two orders of magnitude higher than that in the APSIS experiment.

[45] The higher productions in PAMPRE and in the reactor of Imanaka \& Smith may result from their higher energy deposition. In APSIS, the production is lower than that in the Titan atmosphere despite a higher photon influx (Figure 1). This could be due to a much shorter residence time of the gas: a few hundred seconds in the APSIS reactor (Table 1) compared to $10^{7}-10^{8} \mathrm{~s}$ in Titan's stratosphere [Lebonnois et al., 2001].

[46] More important is the distribution among the products, in particular the ratio between the intensities at $\mathrm{m} / \mathrm{z} 26$ and 27 , corresponding on a first approach to the mixing ratios of $\mathrm{C}_{2} \mathrm{H}_{2}$ and HCN. Both the synchrotron radiation study at $60 \mathrm{~nm}$ and the PAMPRE plasma experiments measure a significantly higher intensity at $m / z 27$, in opposition to the INMS and the APSIS mass spectra.

[47] Other nitrogen-bearing species, $\mathrm{CH}_{3} \mathrm{CN} \mathrm{m} / z$ 41, and $\mathrm{C}_{2} \mathrm{~N}_{2} \mathrm{~m} / z 52$ are detected in Titan and in the APSIS and PAMPRE reactors but not significantly in the synchrotron experiment of Imanaka \& Smith (only an upper limit for $\mathrm{CH}_{3} \mathrm{CN}$ is provided by their $\mathrm{MS}$ deconvolution analysis) [Imanaka and Smith, 2010]. $\mathrm{CH}_{3} \mathrm{CN}$ and $\mathrm{C}_{2} \mathrm{~N}_{2}$ are both produced by reactions involving atomic nitrogen as a reactant: $N\left({ }^{2} \mathrm{D}\right)+\mathrm{C}_{2} \mathrm{H}_{4} \rightarrow \mathrm{CH}_{3} \mathrm{CN}+\mathrm{H}$ and $\mathrm{CHCN}+\mathrm{N} \rightarrow \mathrm{C}_{2} \mathrm{~N}_{2}+$ $\mathrm{H}$, respectively.

[48] Nitrogen atoms are also efficiently adsorbed on the reactor walls. Therefore, we can suspect in the case of Imanaka $\&$ Smith that a lower pressure decreases the bimolecular reaction rate to benefit atomic nitrogen adsorption on the walls (M. Smith, personal communication).

[49] Overall, in spite of systematic lower productions rates, the APSIS reactor provides a new complementary tool to simulate Titan atmospheric reactivity. In the future, the low production efficiency could be improved by either decreasing the pressure in the reactor or prolonging the residence time of the reactive gas. 


\section{Conclusion}

[50] A new reactor, named APSIS (Atmospheric Photochemistry Simulated by Synchrotron), has been designed to simulate planetary atmospheric photochemistry processes. We report here a study focusing on Titan's upper atmosphere. We used a nitrogen-methane gas flow irradiated by a continuous $60-350 \mathrm{~nm}$ VUV beam provided by the DISCO line at the SOLEIL synchrotron radiation facility. The neutral photochemical products were monitored by mass spectrometry, showing a time scale of about $15 \mathrm{~min}$ and a measurable production of species with two up to four (probably five) heavy atoms. The $\mathrm{C} 2$ hydrocarbons are by far the major products, but nitrogen-bearing species such as $\mathrm{HCN}, \mathrm{CH}_{3} \mathrm{CN}$, and $\mathrm{C}_{2} \mathrm{~N}_{2}$ were also detected, in agreement with Cassini's INMS observations at Titan.

[51] We compared the mass spectra with those obtained by a plasma experiment [Carrasco et al., 2012] and with another synchrotron-based experiment [Imanaka and Smith, 2010], and with the in situ measurements of the INMS mass spectrometer instrument on board Cassini probing the neutral content of the Titan upper atmosphere. In spite of lower photochemical production efficiency and different environmental conditions, the APSIS reactor seems to simulate Titan's neutral composition rather well. Nevertheless, its production efficiency should be improved in the future by increasing the residence time of the gas in the reactor.

[52] The pressure in the reactor is higher than that in the Titan upper atmosphere. The main differences expected on the chemistry compared to Titan are developed in a review paper [Cable et al., 2012]: influence of termolecular reactions and more efficient quenching of excited states. Nevertheless, working at higher pressure is mandatory for adapting the mean free path of the reactants to the reactor scale. Seeing that none of the simulation experiments previously discussed convincingly reproduces the neutral compounds in the Titan atmosphere at both levels of species identity and relative amounts, we are performing in parallel a modeling study, to help interpret these simulation experiments and to improve their performance.

[53] Overall, the feasibility of the novel APSIS experiment, for atmospheric photochemistry simulation, has been demonstrated in this study, showing the great interest of this platform for further investigation of planetary atmospheres.

[54] Acknowledgments. The conception and construction of reactor APSIS were supported by the Centre National d'Etude Spatiale and the PRES UniverSud Paris. A. Mahjoub thanks the ANR-JCJC-0038 contract for a postdoctoral position. Experiments were performed on the DISCO beamline at SOLEIL Synchrotron, France (proposal numbers 20100104 and 20100723). We are grateful to the SOLEIL staff for smoothly running the facility. D.P.Q. Nguyen is also acknowledged for his work during his master training period on the pressure dependency of the $I_{14} / I_{28}$ ratio in the MS.

\section{References}

Ádámkovics, M., and K. A. Boering (2003), Photochemical formation rates of organic aerosols through time-resolved in situ laboratory measurements, J. Geophys. Res., 108(E8), 5092. doi:10.1029/2002JE002028.

Alcouffe, G., M. Cavarroc, G. Cernogora, F. Ouni, A. Jolly, L. Boufendi, and C. Szopa (2010), Capacitively coupled plasma used to simulate Titan's atmospheric chemistry, Plasma Sources Sci. Technol., 19(1), 015008. doi:10.1088/0963-0252/19/1/015008.

Breth, A., R. Dobrozemsky, and G. Schwarzinger (1983), Some basic problems in the deconvolution of gas-analytical mass spectra, Int. J. Mass Spectrom. Ion Phys., 48, 3-6. doi:10.1016/0020-7381(83)87014-4.
Cable, M. L., S. M. Hoerst, R. Hodyss, P. M. Beauchamp, M. A. Smith, and P. A. Willis (2012), Chem. Rev., 112(3), 1882-1909.

Carrasco, N., O. Dutuit, R. Thissen, M. Banaszkiewicz, and P. Pernot (2007), Uncertainty analysis of bimolecular reactions in Titan ionosphere chemistry model, Planet. Space Sci., 55(1-2), 141-157. doi:10.1016/j. pss.2006.06.004.

Carrasco, N., T. Gautier, E. Essebbar, P. Pernot, and G. Cernogora (2012), Volatile products controlling Titan's tholins production, Icarus, 219(1), 230-240. doi:10.1016/j.icarus.2012.02.034.

Carrasco, N., et al. (2009), Chemical characterization of Titan's tholins: Solubility, morphology and molecular structure revisited, J. Phys. Chem. $A, 113(42), 11195-11203$. doi:10.1021/jp904735q.

Cravens, T. E., et al. (2006), Composition of Titan's ionosphere, Geophys. Res. Lett., 33, L07105, doi:10.1029/2005GL025575.

Dobrijevic, M., and I. Dutour (2006), A random graphs model for the study of chemical complexity in planetary atmospheres, Planet. Space Sci., 54(3), 287-295. doi:10.1016/j.pss.2005.10.001

Gautier, T., N. Carrasco, A. Buch, C. Szopa, E. Sciamma-O’Brien, and G. Cernogora (2011), Nitrile gas chemistry in Titan atmosphere, Icarus, 213(2), 625-635, doi:doi:10.1016/j.icarus.2011.04.005.

Giuliani, A., et al. (2009), DISCO: A low-energy multipurpose beamline at synchrotron SOLEIL, J. Synchrotron Radiat., 16(6), 835-841, doi:10.1107/S0909049509034049.

Giuliani, A., et al. (2011), A differential pumping system to deliver windowless VUV photons at atmospheric pressure, J. Synchrotron Radiat., 18(4), 546-549, doi:doi:10.1107/S0909049511016517.

Imanaka, H., and M. A. Smith (2007), Role of photoionization in the formation of complex organic molecules in Titan's upper atmosphere, Geophys. Res. Lett., 34(2), L02204, doi:10.1029/2006gl028317.

Imanaka, H., and M. A. Smith (2010), Formation of nitrogenated organic aerosols in the Titan upper atmosphere, Proc. Natl. Acad. Sci., 107(28), 12423-12428. doi:10.1073/pnas.0913353107.

Jennings, D. E., et al. (2012), Seasonal disappearance of far-infrared haze in Titan's stratosphere, Astrophys. J., 754, L3, doi:10.1088/2041-8205/ 754/1/L3.

Larsson, M., W. D. Geppert, and G. Nyman (2012), Ion chemistry in space, Rep. Prog. Phys., 75(6), 066901. doi:10.1088/0034-4885/75/6/066901.

Lavvas, P., R. V. Yelle, and V. Vuitton (2009), The detached haze layer in Titan's mesosphere, Icarus, 201(2), 626-633.

Lebonnois, S. b., D. Toublanc, F. Hourdin, and P. Rannou (2001), Seasonal variations of Titan's atmospheric composition, Icarus, 152(2), 384-406. doi:10.1006/icar.2001.6632.

Listgarten, J., and A. Emili (2005), Statistical and computational methods for comparative proteomic profiling using liquid chromatography-tandem mass spectrometry, Mol. Cell. Proteomics, 4(4), 419-434. doi:10.1074/ mcp.R500005-MCP200.

Mandt, K. E., J. J. H. Waite, B. Teolis, B. A. Magee, J. Bell, J. Westlake, C. Nixon, O. Mousis, and J. Lunine (2012), The $12 \mathrm{C} / 13 \mathrm{C}$ ratio on Titan from Cassini INMS measurements and implications for the evolution of methane, Astrophys. J., 749(2), 160. doi:10.1088/0004-637X/749/2/160.

Mao, F. M., and J. H. Leck (1987), The quadrupole mass spectrometer in practical operation, Vacuum, 37, 669-675. doi:10.1016/0042-207X(87) 90053-4.

Nixon, C. A., et al. (2012), Isotopic ratios in Titan's methane: Measurements and modeling, Astrophys. J., 749(2), 159. doi:10.1088/0004-637X/749/2/159.

Romanzin, C., Y. Bénilan, A. Jolly, and M. C. Gazeau (2008), Photolytic behaviour of methane at Lyman- $\alpha$ and $248 \mathrm{~nm}$ : Studies in the frame of a simulation program of Titan's atmosphere (S.E.T.U.P.), Adv. Space Res., 42(12), 2036-2044. doi:10.1016/j.asr.2008.04.011.

Sagan, C., B. N. Khare, and W. R. Thompson (1993), Polycyclic aromatic hydrocarbons in the atmospheres of Titan and Jupiter, Astrophys. J., 414, 399-405. doi:10.1086/173086.

Sciamma-O'Brien, E., N. Carrasco, C. Szopa, A. Buch, and G. Cernogora (2010), Titan's atmosphere: An optimal gas mixture for aerosol production?, Icarus, 209(2), 704-714. doi:10.1016/j.icarus.2010.04.009.

Szopa, C., G. Cernogora, L. Boufendi, J.-J. Correia, and P. Coll (2006), PAMPRE: A dusty plasma experiment for Titan's tholins production and study, Planet. Space Sci., 54, 394-404. doi:10.1016/j. pss.2005.12.012.

Thejaswini, H. C., A. Majumdar, T. Maung Tun, and R. Hippler (2011), Plasma chemical reactions in $\mathrm{C}_{2} \mathrm{H}_{2} / \mathrm{N}_{2}, \mathrm{C}_{2} \mathrm{H}_{4} / \mathrm{N}_{2}$, and $\mathrm{C}_{2} \mathrm{H}_{6} / \mathrm{N}_{2}$ gas mixtures of a laboratory dielectric barrier discharge, Adv. Space Res., 48 (5), 857-861. doi:10.1016/j.asr.2011.04.020.

Tilford, C. R. (1994), Process monitoring with residual gas analysers (RGAs): Limiting factors, Surf. Coat. Technol., 68/69, 708-712. doi:10.1016/0257-8972(94)90242-9.

Trainer, M. G., A. A. Pavlov, D. B. Curtis, C. P. McKay, D. Worsnop, A. E. Delia, D. W. Toohey, O. B. Toon, and M. A. Tolbert (2004), Haze aerosols in the atmosphere of early Earth: Manna from heaven, Astrobiology, 4, 409-419, doi:doi:10.1089/ast.2004.4.409. 


\section{PENG ET AL : IONOSPHERES SIMULATION EXPERIMENT}

Vuitton, V., R. Yelle, and V. Anicich (2006), The nitrogen chemistry of Titan's upper atmosphere revealed, ApJ, 647(2), L175, doi:10.1086/507467.

Vuitton, V., R. V. Yelle, and M. J. McEwan (2007), Ion chemistry and $\mathrm{N}$-containing molecules in Titan's upper atmosphere, Icarus, 191(2), 722-742. doi:10.1016/j.icarus.2007.06.023.

Waite, J. H., Jr. et al. (2005), Ion neutral mass spectrometer results from the first flyby of Titan, Science, 308, 982-986. doi:10.1126/science.1110652.
Waite Jr, J. H., D. T. Young, J. Westlake, J. I. Lunine, C. P. McKay, and W. S. Lewis (2009), High-altitude production of Titan's aerosols, in Titan From Cassini-Huygens, edited by R. H. Brown, J.-P. Lebreton and J. H. Waite, pp. 201-214, Springer, Dordrecht Heidelberg London New York. Waite Jr., J. H., D. T. Young, T. E. Cravens, A. J. Coates, F. J. Crary, B. Magee, and J. Westlake (2007), The process of tholin formation in Titan's upper atmosphere, Science, 316, 870-875, doi:10.1126/science.1139727. 